\title{
LA REVISION DE PRECIOS DE LOS CONTRATOS DE OBRAS DE LAS ADMINISTRACIONES LOCALES
}

$352.071(46)$

por

José M: Boquera Oliver

Catedrático de Derecho administrativo

SUMARIO: I. LA MODIFICACION CONVENIDA DEL PRECIO DE LOS CONTRATOS DE OBRAS DE LAS ADMINISTRACIONES LOCALES: 1. La VALIDEZ DE LAS CLÁUSUlas DE MODIFICACIÓN DEL PRECIO EN LOS CONTRATOS DE OBRAS. 2. LAS CLAUSULAS DE MODIFICACIÓN DE LOS PRECIOS SE APLICAN CON PREFERENCIA A LAS DISPOSICIONES LEGALES Y REGLAMENTARIAS SOBRE LA MISMA MATERIA. 3. LA VALIDEZ DE LAS CLAUSULAS DE MODIFICACIÓN DE LOS PRECIOS EN LOS CONTRATOS DE OBRAS DE LAS ADMINISTRACIONES LOCALES: A) Las normas reglamentarias. B) Clases de cláusulas de modificación de los precios. Validez de las cláusulas de variación $e$ invalidez de las cláusulas de revisión.-II. LA REVISION DE PRECIOS DE LOS CONTRATOS DE LA ADMINISTRACION LOCAL POR APLICACION DE UN PRECEPTO REGLAMENTARIO: 1. El artículo 57, 1, e), del Reglamento de Contratación DE LAS Corporaciones locales. Sus antecedentes. 2. La vigencia aCtual del artfculo 57, 1, e), del Reglamento de Contratación de las Corioraciones locales: A) Tesis negativa. B) Tesis positiva.-III. EL DECRETO DE 31 DE MAYO DE 1974 REGULADOR DE LA REVISION DE PRECIOS DE LOS CONTRATOS DE LA ADMINISTRACION LOCAL: 1. Finalidad del Decreto de 31 de Mayo DE 1974. 2. La Naturaleza juRfdica del Decreto de 31 de mayo de 1974. 3. Las fórMulas tipo. 4. El Decreto de 31 de Mayo de 1974 Y la Vigencia del artfculo 57, 1, e), del Reglamento de Contratación de las CorporaCIONES LOCALES. 


\section{LA MODIFICACION CONVENIDA DEL PRECIO DE LOS CON- TRATOS DE OBRAS DE LAS ADMINISTRACIONES LOCALES}

\section{La VALIDEZ dE LAS CláUSULAS DE MOdIFICACIÓN DEL PRECIO EN LOS CONTRATOS DE OBRAS}

El Derecho contractual moderno trata de remediar las consecuencias de las fluctuaciones económicas y monetarias sobre la ejecución de los contratos celebrados con anterioridad a dichas fluctuaciones, incluyendo en los contratos cláusulas de revisión de los precios que se aplicarán cuando cambie la coyuntura económica.

Estas cláusulas son válidas porque, como dice el artículo 1.255 del Código civil, alos contratantes pueden establecer los pactos, cláusulas y condiciones que tengan por conveniente, siempre que no sean contrarias a las leyes, a la moral ni al orden público». Las cláusulas de revisión de los precios, con el propósito de mantener el equilibrio económico del contrato, no sólo no son contrarias a las leyes, a la moral o al orden público, sino que obedecen a un indudable principio de equidad social y de justicia distributiva, al igual que las disposiciones legales revisoras, según declara, en relación con estas últimas, la jurisprudencia del Tribunal Supremo (1).

Estas cláusulas son, en definitiva, una manifestación de la libertad de los contratantes para la determinación del contenido del contrato (auto-regulación) que deriva, como pone de relieve A. HERNÁNDEZ GIL (2), del principio de la autonomía de la voluntad que rige la actividad contractual.

La anterior conclusión es aplicable a toda clase de contratos, pues lo dispuesto por el artículo 1.593 del Código civil, con respecto al contrato de obras - ael arquitecto o contratista que se encarga por un ajuste alzado de la construcción de un edificio u otra obra en vista de un plano convenido con el propietario del suelo, no puede pedir aumento de precio aunque se haya aumentado el de los jornales o materiales...»-, no se impone a las partes contratantes, sino que sólo se aplica a los contratos de obras en defecto de pacto sobre la revisión del precio de los mismos.

La regla del artículo 1.593 del Código civil también puede dejar

(1) Sentencias de 14 de noviembre de 1943 y 14 de noviembre de 1953.

(2) Derecho de obligaciones, Madrid, 1960, págs. 228 y 229. 
de aplicarse en virtud de disposiciones reglamentarias, y, en casos extremos, por los jueces, que tienen la posibilidad de aplicar principios jurídicos superiores a la fuerza obligatoria de las convenciones, como son el de la cláusula sobreentendida rebus sic stantibus, el riesgo imprevisible, la alteración de la base del negocio, etc.

La sentencia de 4 de mayo de 1961 dice que «el beneficio de la revisión de precios puede tener dos orígenes: uno, de indole genérica y automática, cuando se comprueba la existencia de las condiciones señaladas para ello por el legislador en un contrato de obras o suministros...; y otro de índole específica y paccionada, cuando ha mediado la correspondiente estipulación legalmente autorizada que obligue a la Administración en el contrato concreto a que se refiere». Ahora estudiamos la modificación paccionada de los precios de los contratos.

2. LAS CLAUSULAS DE MODIFICACIÓN DE LOS PRECIOS SE APLICAN CON PREFERENCIA A LAS DISPOSICIONES LEGALES Y REGLAMENTARIAS SOBRE LA MISMA MATERIA

Cuando en un contrato existen cláusulas de revisión de su precio prevalecen frente a las disposiciones legales o reglamentarias sobre revisión de los precios de los contratos. Procede la aplicación de lo pactado y no lo dispuesto por las leyes o reglamentos. Así lo proclamaba claramente el artículo 11 de la Ley de Revisión de precios de 17 de julio de 1945: "Tampoco serán de aplicación sus preceptos (los de la Ley) en aquellos contratos en que estén previstos los casos de revisión o forma de llevarla a cabo, en los que se estará a lo especialmente pactado en cada uno de ellos». La Ley de Contratos del Estado de 8 de abril de 1963, aunque menos claramente, mantiene igual postura en sus artículos $7 .^{\circ}$ (en relación con el posterior Decreto-ley de 4 de febrero de 1964), 73 y 91

La jurisprudencia mantiene constantemente la tesis de que el pacto de revisión prevalece sobre las disposiciones legales vigentes, cualquiera cual sea su contenido. Así las sentencias de 9 de mayo de 1950, 20 de octubre de 1958 y 7 de octubre de 1961(3).

(3) La sentencia de 8 de noviembre de 1958 declara que ael último inciso del artículo 11 de la Ley de 17 de julio de 1945 somete las revisiones de precios a lo que especialmente se haya convenido en aquellos contratos en que estén 
aEsta postura jurisprudencial es inveterada», dice ARIÑo OrTIZ (4), y cita a Delgado Martin que, en un libro publicado en 1883 (segunda edición, 1899), sobre Contratos administrativos de obras $y$ servicios públicos, recoge sentencias en este sentido.

Tan poderosa es la voluntad en esta materia que el contratista puede renunciar al derecho que la ley le concede a revisar su contrato (5). No puede sorprender, pues, sino que se comprende perfectamente, que los contratantes puedan pactar la revisión de los precios de sus contratos, aunque las leyes no establezcan dicha revisión, y que, en el caso de que existan leyes de revisión de los precios contractuales, lo convenido se aplique con preferencia a lo dispuesto legalmente.

Cuando el contrato mismo ha previsto el medio de restablecer el equilibrio entre la prestación y el precio, si acontecimientos exteriores al contrato lo han roto, el contratista tiene derecho al restablecimiento de dicho equilibrio.

3. LA VALIDEZ DE LAS CLAUSULAS DE MODIFICACIÓN DE LOS PRECIOS EN LOS CONTRATOS DE OBRAS DE LAS ADMINISTRACIONES lOCALES

\section{A) Las normas reglamentarias}

El Reglamento de Contratación de las Corporaciones locales de 9 de enero de 1953 dispone en su artículo 21, 2, que «el pliego de condiciones, subordinado a este Reglamento, constituirá la ley del contrato, con fuerza vinculante para ambas partes". Por consiguiente, serán válidas todas las cláusulas del pliego particular del contrato que no contradigan dicho Reglamento. En cambio, no ten-

previstos los casos de revisión o forma de llevarla a cabo, y la escritura en que consta el de autos, contiene en su cláusula octava un pacto expreso de revisión determinativo de cuándo ha de proceder ésta y forma de realizarse, por lo que se ha de estar al mismo para su observancia en el momento en que, con arreglo a tal cláusula, pueda aquella revisión tener lugar. No puede aplicarse, por tanto, como se ha hecho en la Orden impugnada, el artículo 1.० de la Ley referida, que excluye de la revisión de precios los contratos que no hayan sido adjudicados mediante subasta o concurso, porque si bien por el precepto dicho queda privada de tal beneficio revisorio, en cambio, por el artículo 11 y la cláusula 8." ya aludidos, hay la posibilidad de que pueda alcanzarlo».

(4) Teoria del equivalente económico en los contratos administrativos, Madrid, Instituto de Estudios Administrativos, 1968, pág. 335.

(5) Sentencias de 17 de marzo de 1959, 28 de febrero de 1966 y 15 de enero de 1971. 
drán validez las cláusulas del pliego contrarias al Reglamento de Contratación de las Corporaciones locales.

En el Reglamento de 9 de enero de 1953 existen dos preceptos cuyo significado conviene examinar para poder apreciar si es posible o no incluir en los pliegos particulares de condiciones -que le deben estar subordinados- cláusulas de revisión de los precios de los contratos.

El primero de ellos es el artículo 51, y el segundo el artículo 57.

El artículo 51 del Reglamento de Contratación de las Corporaciones locales dice que «los contratos serán inalterables a partir de su perfeccionamiento, y deberán ser cumplidos con estricta sujeción a sus cláusulas y a los pliegos que les sirvan de base, cuyas condiciones jurídicas, técnicas y económicas sólo podrán modificarse mediante una nueva licitación, salvo las excepciones expresamente admitidas por los artículos siguientes».

La inalterabilidad de los contratos de la Administración local, a diferencia de la posibilidad de modificar por mutuo acuerdo los contratos celebrados entre particulares, deriva del hecho de que a aquéllos les preceden procedimientos especiales (subasta, concurso o concurso-subasta) para elegir al contratista. Al iniciarse dichos procedimientos, la Administración fija y anuncia las condiciones que deberán reunir las ofertas de los licitadores para poder ser aceptadas. De conformidad con tales condiciones presentan los licitadores sus ofertas, y a la mejor oferta se le adjudica el contrato. El contenido de éste lo constituyen precisamente las condiciones de los pliegos particulares. Si una vez perfeccionado el contrato, la Administración, de acuerdo con el contratista, pudiera modificar lo convenido, la previa subasta, el concurso o el concurso-subasta perderían su razón de ser, puesto que la prestación solicitada, el precio ofrecido y demás condiciones exigidas en el pliego nada sig. nificaron. Como dichos procedimientos tienen como finalidad salvaguardar los intereses de la hacienda pública y el principio de igualdad de los administrados ante los beneficios y cargas públicas, la alteración del contrato ya perfeccionado lesionaría a unos y a otro (6). La sentencia de 3 de agosto de 1957 manifiesta que "en las convenciones específicas de Derecho pública... prevalece y es preocupación primordial el interés público; la defensa de estos

(6) En mi trabajo Poder administrativo y contrato, Escuela Nacional de Administración Pública, 1970, especialmente págs. 70 a 80 , pueden verse un poco más desarrolladas las afirmaciones del texto. 
intereses impide modificaciones de las bases y cláusulas del contrato en que la concesión se traduzca, ya que de ser conocidas en su tiempo tales modificaciones pudieran influir en la concurrencia de otros licitadores y en la obtención de condiciones favorables para el propio interés público».

Por su parte, el artículo 57 del Reglamento de Contratación de las Corporaciones locales dice que «los contratos en que intervengan las Corporaciones locales se entenderán siempre convenidos a riesgo y ventura para el contratista, sin que éste pueda solicitar alteración del precio o indemnización, excepto por alguna de las...» causas que enumera el mismo artículo.

Debemos preguntarnos si las cláusulas de alteración de precios contradicen o no los principios de la inalterabilidad de los contratos de la Administración local y el de que éstos se celebran siempre a «riesgo y ventura para el contratista», que el Reglamento de Contratación de 9 de enero de 1953 establece de manera muy clara.

B) Clases de cláusulas de modificación de los precios. Validez de las cláusulas de variación e invalidez de las cláusulas de revisión

En nuestro Derecho positivo, las denominadas cláusulas de revisión pueden ser de dos clases. Unas que, ante el cambio de la coyuntura económica, funcionan automáticamente y calculan matemáticamente el importe de la elevación de los precios, y otras que se limitan a reconocer al contratante interesado en la modificación del precio el derecho a reclamarla sin fijar el elemento cuantitativo de la misma. Las primeras son denominadas por los autores franceses -así, por ejemplo, DE LAUBADĖRE (7)- cláusulas de variación $\mathrm{y}$, las segundas, cláusulas de revisión.

Las cláusulas de variación se expresan mediante fórmulas matemáticas que automáticamente toman en cuenta la entidad del cambio económico que justifica la modificación del precio del contrato y de la misma forma calculan el montante de la variación del precio en función de la èntidad del cambio económico. Ejemplo de estas cláusulas son las fórmulas polinómicas que para los contratos del

(7) Traité théorique et pratique des contrats administratifs, París, L. G. D. J., 1956, II, pág. 290. 
Estado regulan el Decreto-ley de 4 de febrero de 1964 y sus disposiciones complementarias.

Las cláusulas de revisión, propiamente dichas, ante un cambio económico abren la posibilidad de que las partes contratantes reclamen la modificación del precio del contrato y permiten que de mutuo acuerdo fijen el importe de aquélla. Son, suele decirse, cláusulas de principio.

Las cláusulas de variación de los precios de los contratos no son contrarias al principio de inalterabilidad de los mismos, pues ni atentan contra el principio de igualdad, en el trato a los licitadores, ni perjudican los intereses de las haciendas públicas, pues éstas no pueden pretender obtener ganancias injustificadas. Al figurar dichas cláusulas en los pliegos particulares de condiciones, los licitadores saben que si se altera la coyuntura económica todos serán tratados por igual, pues la fórmula matemática no tiene en cuenta ninguna circunstancia subjetiva, ni puede tenerla, para fijar la cuantía de la variación del precio. La modificación del precio será ajena a todo partidismo o favoritismo. De otro lado, la Administración contratante no debe aprovecharse de una alteración de la coyuntura económica en perjuicio grave del contratista, ni le resulta interesante el hundimiento de sus colaboradores los contratistas (8). Las cláusulas de variación salvaguardan los principios que sirven de fundamento a la inalterabilidad de los contratos de la Administración pública y son por eso compatibles con ella.

La Ley de Contratos del Estado, de 8 de abril de 1965, demuestra también que las cláusulas de variación son compatibles con el principio de inalterabilidad de los contratos. En su artículo $7 .^{\circ}$ declara que «la inclusión de cláusulas de revisión de precios se regulará por su legislación especial» (9), y en su artículo 48 proclama el principio de inalterabilidad. El Reglamento de Contratos del Estado de 28 de diciembre de 1967 dice muy claramente en su artículo 151, que no "tendrá carácter de modificación la alteración del precio por aplicación de cláusulas de revisión...». Lo que ocurre, como después veremos, es que las denominadas cláusulas de revisión son en realidad cláusulas de variación.

(8) Cfr. Garrido Falla, F, aEn torno a una posible reforma de la legislación sobre la contratación de obras públicas», en Documentación Administrativa, nú. mero 55, 1962.

(9) Esta legislación es básicamente el Decreto-ley de 4 de febrero de 1964, que regula, en realidad, cláusulas de variación. 
Lo demuestran también las legislaciones de muchos países extranjeros, que admiten la inclusión de fórmulas polinómicas en los pliegos de condiciones para variar los precios de los contratos y simultáneamente proclaman y respetan la inalterabilidad de los contratos.

En cambio, las cláusulas de revisión propiamente dichas no son posibles en los pliegos particulares de condiciones de los contratos de la Administración local, porque al abrir la discusión sobre el quantum de la revisión de los precios y poderse éste fijar de mutuo acuerdo por las partes contratantes, contradicen el principio de inalterabilidad de sus contratos.

El principio de que el contrato se celebra a «riesgo y ventura del contratista" también es compatible con las cláusulas de variación. En primer lugar, porque aquél no es un imperativo reglamentario, sino una cláusula contractual prevista reglamentariamente - "los contratos... se entenderán siempre convenidos a riesgo y ventura para el contratista» (art. 57 del Reglamento de Contratación de las Corporaciones locales)-, que sólo tiene aplicación cuando no se pacta de manera expresa la distribución del riesgo y la ventura entre las dos partes del contrato. «Debe recordarse - dice la sentencia de 4 de mayo de 1961- que la contratación pública... reposa en España en el viejo principio de riesgo y ventura del que sólo cabe separarse cuando concurren los taxativos motivos definidos por el legislador imperativamente, o por la voluntad de las partes dentro de lo autorizado por aquél».

En el Reglamento de Contratación municipal de 2 de julio de 1924 , anterior al vigente, su artículo $60^{\circ}$ decía que «en el pliego de condiciones se consignarán necesariamente los casos en que el rematante pueda pedir aumento o disminución del precio o rescisión del contrato, o la advertencia de que éste se hace a riesgo y ventura para el rematante, sin que por ninguna causa pueda pedir alteración del precio o rescisión". El criterio actualmente vigente es el mismo de 1924, con la diferencia de que con el artículo 57 del Reglamento de 1953 no es necesario mencionar en el pliego particular de condiciones que el contrato se celebra «a riesgo y ventura del contratista».

La doctrina ha demostrado(10) que el principio de riesgc y ventura también rige en la contratación entre particulares (artícu-

(10) Garcfa de Enterria, E., aRiesgo y ventura y fuerza mayor en el contrato administrativon, Revista de Administración Pública, núm. 2, pág. 87. 
los $1.589,1.590$ y 1.596 del Código civil), y en los contratos civiles son posibles los pactos sobre el reparto entre los contratantes de los riesgos y venturas que pueden presentarse durante la ejecución del contrato.

En segundo lugar, prueban que las cláusulas de variación no se oponen al artículo 57 del Reglamento de Contratación de las Corporaciones locales las declaraciones jurisprudenciales que reconocen la validez de aquéllas en contratos de la Administración local (sentencias de 20 de octubre de 1958 y 7 de octubre de 1961) y también el dictamen del Consejo de Estado de 25 de septiembre de 1946, expediente 2.031 (Recopilación de Doctrina legal 19451946, núm. 32).

Finalmente, la Ley de Contratos del Estado proclama en su artículo 46 el principio de la ejecución del contrato «a riesgo y ventura del contratista", y en su artículo $7 .^{\circ}$ prevé la inclusión de las que llama cláusulas de revisión de precios de los contratos, aunque, como hemos dicho, son de variación.

\section{LA REVISION DE PRECIOS DE LOS CONTRATOS DE LA ADMINISTRACION LOCAL POR APLICACION DE UN PRE- CEPTO REGLAMENTARIO}

1. El artfculo 57, 1, e), del Reglamento de Contratación de las CORPORACIONES LOCALES. SUS ANTECEDENTES

En 1945, el Estado español pensó que a los adjudicatarios de obras públicas se les estaban causando graves perjuicios con los aumentos en «los importes de los materiales y de la mano de obra autorizados posteriormente (a la adjudicación) por órdenes emanadas de la Administración pública, desconocidas cuando tuvo lugar la adjudicación", lo que también ocurriría en el futuro. Para evitar tales perjuicios, se promulgó la Ley de 17 de julio de 1945, por la que "se autoriza la revisión transitoria de los precios unitarios fijados en los proyectos de obras adjudicadas mediante subasta o concurso por los distintos Departamentos ministeriales con aplicación a las unidades de obras pendientes de ejecución en 1 de julio de 1944, de los aumentos de coste establecidos por disposición de la Administración pública dictada con anterioridad a esta fecha, y posteriormente a la de la adjudicación de la obra, así como de los 
que se acuerden por disposiciones oficiales con fuerza de obligar, publicadas después de 1 de julio de 1944, desde la fecha de su entrada en vigor» (artículo $10^{\circ}$ de la citada Ley).

La revisión de precios se acordará: a) previa solicitud de parte; b) el aumento de los costes de la mano de obra o de los materiales deberá ser "determinado por disposición administrativa oficial»; c) «para que pueda concederse la bonificación de precios de que se trata, es condición indispensable que uno o varios de los precios unitarios del contrato sufran aumento superior al 10 por 100 de su importe», y el presupuesto total de ejecución de la obra una alteración superior al 5 por 100 (art. 2..$^{\circ}$ de la Ley de 1945); d) «la revisión de precios sólo tendrá lugar cuando el contratista no haya incurrido en morosidad al realizar las obras..." (art. 6. de la Ley de 1945).

Por el artículo 13 de la Ley de Revisión de precios, de 17 de julio de 1945, "queda autorizado el Gobierno para suspender la aplicación de los preceptos de esta Ley o acordar su definitiva derogación, cuando las circunstancias así lo aconsejen, mediante Decreto acordado en Consejo de Ministros».

El Decreto de 31 de octubre de 1946 autorizó a las Diputaciones y Ayuntamientos a acogerse, si lo deseaban, a la Ley de 17 de julio de 1945. Pero al redactarse el Reglamento de Contratación de las Corporaciones locales de 9 de enero de 1953 se imitaron los principios básicos de la Ley de 17 de julio de 1945. El artículo 57, 1, del citado Reglamento estableció que «los contratos en que intervengan las Corporaciones locales se entenderán siempre convenidos a riesgo y ventura para el contratista, sin que éste pueda solicitar alteración del precio o indemnización, excepto por alguna de las siguientes causas: ... e) aumentos que excedan del 10 por 100 del precio de los materiales o jornales que de hecho viniere satisfaciendo el contratista, cuando fueren establecidos por precepto obligatorio y no existiere demora imputable a aquél en relación con los plazos señalados por el pliego de condiciones. En los supuestos del párrafo anterior no podrán ser rebasados los coeficientes a que alude el apartado d) del artículo 23, pero sí estimados inferiores». (El apartado d) del artículo 23 se refiere al «cuadro que, bajo la rúbrica "Porcentaje de los elementos de los precios unitarios", descomponga en detalle los que integren el Presupuesto").

Después de 1953 han habido algunos cambios en la regulación 
de la modificación de los precios de los contratos, y como consecuencia de ellos, en estos momentos está sometida a discusión la vigencia del artículo 57, 1, e), del Reglamento de 9 de enero de 1953.

2. La vigencia actual del articulo 57, 1, e), Del Reglamento de Contratación de las Corporaciones locales

\section{A) Tesis negativa}

El parecer de que el repetido artículo no está en vigor puede apoyarse en las razones y datos que exponemos a continuación.

El artículo 57 del Reglamento de Contratación de las Corporaciones locales no es la aplicación a las Administraciones locales de lo dispuesto por la Ley de 17 de julio de 1945 sobre la revisión de los precios de los contratos del Estado, sino que es una norma con fuerza propia, nacida del poder reglamentario que la Ley de Régimen local confirió al Gobierno en materia de Administración local. El preámbulo del citado Reglamento dice: "La Ley de Régimen local, aprobada por Decreto de 16 de diciembre de 1950, encomendó al Ministerio de la Gobernación la publicación de los Reglamentos e Instrucciones necesarios para el desarrollo de las normas sustantivas y su adecuada aplicación. En cumplimiento de ese mandato se ha redactado el Reglamento de Contratación de las Corporaciones locales...».

Por consiguiente, el artículo 57 del Reglamento de Contratación de las Corporaciones locales no toma su fuerza de la Ley de 17 de julio de 1945, dictada para la esfera de la Administración estatal, aunque al regular la revisión de los precios de los contratos de la Administración local imita en parte su contenido (no exige, por ejemplo, que la alteración sea superior al 5 por 100 del presupuesto total de ejecución de la obra).

El Tribunal Supremo, en la sentencia de 20 de octubre de 1955, dice que «la Ley de 17 de julio de $1945 \ldots$ no ha sido directamente aplicada a las Corporaciones locales, cuyo régimen legal en la materia estuvo anteriormente expresado en el artículo $6 .^{\circ}$, número 6, del Reglamento de Contratación de 2 de julio de $1924 \ldots$, como hoy lo está en el artículo 57, número 1, apartado e), del Reglamento que le ha sustituido, de 9 de enero de 1953».

Por su parte, la sentencia de 27 de septiembre de 1963 declara 
que «manteniendo los argumentos desenvueltos por la doctrina de este Tribunal - singularmente en las sentencias de 22 de marzo de 1961 y 25 de febrero de 1963 - debe recordarse que los ordenamientos legales que encuadran y definen los derechos y deberes de los contratantes en el ámbito administrativo, son diferentes según se refieran a la esfera estatal o a la local, sin que pueda calificárseles de absolutamente paralelos y similares, ni establecer una comunicación complementaria que permita extender las peculiaridades sustantivas del primero al segundo; cosa diferente de la aplicación supletoria de los trámites procesales sólo detallados en el primero, por razón de la vigencia anterior y genérica del principio de audiencia de los interesados, es decir, que ha de aplicarse en cada supuesto los preceptos con directa fuerza legal, constituidos en el caso de autos por el Decreto de 22 de febrero de 1957 y la Orden de 17 de julio siguiente, en relación con los Reglamentos de Contratación y de Servicios de las Corporaciones locales, estando a cuanto en ellos se prevé, define y manda, respecto de las consecuencias que debe alcanzar la revisión de precios, sin que tampoco sea función de los Tribunales de esta jurisdicción mejorar el sentido de los preceptos que aplican, sino verificar su adecuación a los actos que revisan».

La jurisprudencia que acabamos de recordar pone de relieve la independencia entre la Ley de 17 de julio de 1945 y el Reglamento de 9 de enero de 1953.

La revisión de los precios por aplicación de la Ley de 17 de julio de 1945 (no las modificaciones de los precios pactadas) fue suspendida, en virtud de la autorización concedida al Gobierno por el artículo 13 de la misma Ley, por el Decreto de 13 de enero de 1955.

El artículo 57, 1, e), del Reglamento de Contratación de las Corporaciones locales también fue suspendido por otro Decreto de 25 de febrero de 1955, para "mantener el paralelismo - dice su preámbulo- entre el régimen jurídico de la contratación administrativa local y el que rige en la esfera central». Pero el hecho de que se dictara el Decreto de 25 de febrero de 1955 para suspender la eficacia del citado precepto del Reglamento de Contratación, demuestra que el Decreto de 13 de enero de 1955, dictado para suspender la Ley de 1945, no era suficiente para dejar sin efecto el artículo 57, 1, e), del Reglamento de Contratación de las Corporaciones locales. Como decía la sentencia de 16 de marzo de 1961, 
«superadas las alteraciones económicas que originaron la publicación de la Ley de revisión, el Decreto de 13 de enero de 1955 dejó en suspenso la mencionada Ley en la esfera central, y el de 25 de febrero del mismo año hizo lo propio en la esfera local, siendo desde entonces paralelas, aunque independientes, las normas que vienen regulando las revisiones en ambas esferas». Las normas paralelas, pero, naturalmente, independientes, como todo lo paralelo.

Después se dictaron algunas disposiciones que autorizaron en diferentes épocas la compensación de precios en la esfera central y paralelamente en la local (Decreto-ley de 18 de enero de 1957 para los contratos del Estado, y Decreto de 22 de febrero de 1957 para los de las Administraciones locales; Decreto de 22 de mayo de 1963 para la contratación estatal, y el Decreto de 17 de octubre de 1963 para las Corporaciones locales).

En 1963, el Decreto-ley de 10 de octubre autorizó la inclusión de cláusulas de revisión (en realidad eran cláusulas de variación) de precios en los contratos de obras del Estado, y derogó expresamente (Disposición final) a la Ley de 17 de julio de 1945, que estaba en suspenso desde el Decreto de 13 de enero de 1955. Poco después, el Decreto-ley de 4 de febrero de 1964, sobre la misma materia, derogó el Decreto-ley antes citado, y también de manera expresa (Disposición final segunda) la Ley de 17 de julio de 1945. Derogada dicha Ley, el Decreto de 13 de enero de 1955 no tenía ya razón de existir. También quedó, pues, sin ningún valor, aunque no se le derogó expresamente.

Pero el artículo 57, 1, e), del Reglamento de 9 de enero de 1953, como no es aplicación ni desarrollo de la Ley de 17 de julio de 1945, sino simple imitación de su contenido por la Administración del Estado al ejercitar su propio poder reglamentario, no quedó derogado al derogarse la tan repetida Ley. Aquel precepto reglamentario no guardaba con la Ley de 1945 ningún vínculo jurídico. Eran normas paralelas, pero independientes. El Decreto de 25 de febrero de 1955, que suspendió la eficacia del también tan repetidamente citado precepto reglamentario, tampoco guardó jamás ninguna relación con la Ley de 17 de julio de 1945, y mucho menos con el Decreto de 13 de enero de 1955, que suspendió la eficacia de esta Ley. Derogadas estas dos últimas disposiciones, puede vivir perfectamente el Decreto de 25 de febrero de 1955, que suspende la eficacia de un precepto que no ha sido derogado. 
El Decreto de 17 de octubre de 1963 («B. O. E.» del 2 de noviembre de 1963), dictado cuando ya había entrado en vigor el Decreto-ley de 10 de octubre de 1963 («B. O. E.» del 16 de octubre de 1963) y había sido derogada la Ley de 1945 (Disposición final del citado Decreto-ley), autoriza por una sola vez la compensación de precios en los contratos de la Administración local, lo que no hubiera sido necesario de poderse aplicar el artículo 57, 1, e), del Reglamento de Contratación de las Corporaciones locales.

El Tribunal Supremo (Sala Cuarta) en sentencia de 5 de enero de 1972 declaró que el artículo 57 del Reglamento de Contratación de las Corporaciones locales "quedó definitivamente suspendido por Decreto de 25 de febrero de 1955, y esta suspensión, pese a cuanto alega el recurrente, ya no fue levantada, porque las dos revisiones que autorizaron los Decretos de 22 de febrero de 1957 y 17 de octubre de 1963 lo fueron sobre contratos celebrados en ciertas épocas determinadas..., y además con la expresión de que tales revisiones se hacian por una sola vez; por lo que al no existir disposición alguna que expresamente derogara la suspensión acordada por el Decreto de 25 de febrero de 1955, no cabe duda alguna de que la suspensión subsiste...»(11).

ARIÑo ORTIZ (12) estima vigente, pero en suspenso, el artículo 57, 1, e), del Reglamento de Contratación de las Corporaciones locales.

(11) En el contrato que enjuició la sentencia de 5 de enero de 1972 figuraba pactada en una de sus cláusulas la revisión de precios en la misma forma que está regulada en el artículo 57 del Reglamento de Contratación de las Corporaciones locales. La Audiencia de Sevilla declaró el derecho del contratista a obtener la revisión de precios conforme a lo pactado en la cláusula del pliego de condiciones. En cambio, el Tribunal Supremo declaró que dicha acláusula carece de toda eficacia y fuerza de obligar, desde el momento en que se pactó en contra de lo dispuesto en la Ley...» (la Ley, en este caso, parece que era el Decreto que suspendió la aplicación del artículo 57, 1, e), del Reglamento de Contratación de las Corporaciones locales). En razón de lo que hemos dicho con respecto a la modificación convenida de los precios, creemos que la cláusula podía no ser válida por ser una cláusula de revisión, pero no por ser un pacto de modificación contrario a un precepto reglamentario que suspende las revisiones de precios. Véase RodrfGuez MORo, N., «Sobre la vigencia del artículo 57 del Reglamento de Contratación de las Corporaciones locales en orden a la revisión de precios en las obras contratadas por aquéllas», REvisTa DE ESTUdios DE LA VIDA LOCAL, núm. 175, 1972, pág. 548.

(12) Ob. cit., pág. 341. 


\section{B) Tesis positiva}

El Tribunal Supremo (Sala Cuarta) ha declarado, en su sentencia de 15 de enero de 1971, "que dado el contenido del Decreto de 25 de febrero de 1955, dictado expresa y reconocidamente para mantener el paralelismo entre la legislación referente a revisión de precios de los contratos administrativos del Estado y revisión de precios de los contratos administrativos de las Corporaciones locales, no es posible desligar su fundamentación normativa en la Ley de 17 de julio de 1945, pues es precisamente en el preámbulo del Decreto donde con extensión y claridad se precisa la naturaleza y finalidad del precepto, ya que textualmente expone: "que el Reglamento de Contratación de las Corporaciones locales (de 9 de enero de 1953) autorizó la revisión de precios de los contratos en que intervinieran las Corporaciones locales, siguiendo las directrices de la Ley de 17 de julio de 1945 para la contratación de los distintos Departamentos ministeriales", expresándose a continuación que "dictado el Decreto de 13 de enero de 1955" (o sea, un mes antes), dejando en suspenso la aplicación de los preceptos de la Ley de 17 de julio de 1945 (haciendo uso de su art. 13), "... es lógico mantener el paralelismo entre el régimen jurídico de la contratación administrativa local y el que rige en la central. Las razones que han impulsado al Gobierno a suspender la vigencia de la Ley de Revisión de precios tienen la misma virtualidad en el ámbito local. Se trata, en definitiva, de dos actividades de una misma manifestación jurídica, la contratación administrativa, los principios inspirados de una y otra deben ser, por tanto, idénticos. Ninguna razón justificaría el otorgamiento por parte de las Corporaciones locales en favor de los contratistas de ventajas superiores a las que el propio Estado les reconoce. Ello podría dar lugar a consecuencias económicas lamentables, como sería la emigración de los contratistas desde la esfera central a la local, estableciéndose una suerte de competencia totalmente inadmisible entre Corporaciones de Derecho público", exposición bien clara de que la base del Decreto, respecto al de 13 de enero de 1955, referente a los contratos estatales, como el de 22 de febrero de 1955, referente a los contratos de los entes de la Administración local, en el punto referencial de la Ley de 17 de julio de 1945, o sea, la Ley que establecía la revisión para los contratos administrativos del Estado, y esta 
secuencia reconocida y plasmada en normas, y aun explicada a través del preámbulo citado, vincula, explica y nexa el contenido del Decreto de 25 , le febrero de 1955 al de 13 de enero de 1955, y lo refiere inequivocamente a la Ley de 17 de julio de 1945, derogada por mandato expreso del Decreto-ley de 4 de febrero de 1964 en el número 2 de sus disposiciones finales, como ya lo había sido por el Decreto-ley de 10 de octubre de 1963 en su disposición final única, con lo que se hace necesario procurar el mismo tratamiento a la disposición secuente a la Ley derogada, que a la Ley misma que la precedió y fue indudable inspiradora.... (13).

"Que a mayor abundamiento, ha de tenerse en cuenta que toda la legislación de revisión de precios, como se deduce tanto de sus respectivos contenidos como de los preámbulos, a veces extensos prefacios, que los preceden, no constituyen normas estáticas definitorias de posiciones jurídicas, sino disposiciones oportunistas de naturaleza circunstancial, como típica normativa de coyuntura, tal como lo demuestra la variabilidad de su adaptación a las diversas situaciones económicas que constituyen la ratio legis de cada precepto..., todo lo que hace que deba apreciarse como convincente y racional el argumento que la Sala Territorial califica como "muy estimable", puesto que al integrar tanto la contratación administrativa en la esfera central, como en la local, una misma actividad jurídica, ha de atenerse a una nueva fundamentación racional y exegética, que refuerza la tesis derogatoria del Decreto de 25 de febrero de 1955 y su inaplicabilidad normativa, dado su carácter provisional y contingente, como toda medida suspensoria del orden jurídico, cuya característica esencial es la de repugnar a la idea de permanencia, ya que está constreñida a una validez temporal cuya

(13) Continúa la referida sentencia diciendo que asi el Decreto de 25 de febrero de 1955 para mantener la semejanza entre el régimen jurídico de la contratación administrativa central y la contratación administrativa local, de desaparecer cuantas disposiciones traían de ella causa, sentido que queda perfectamente reflejado en el preámbulo del Decreto-ley de 4 de febrero de 1964, en el que se dice que las disposiciones en él contenidas se publican "no sólo con el fin de unificar en lo posible las normas de revisión de los contratos, sino en dar cumplimiento al artículo 30 de la Ley de Régimen jurídico de la Administración", en el que se establece que "las resoluciones administrativas de carácter particular no podrán vulnerar lo establecido en una disposición de carácter general, aunque aquéllas tengan un grado igual o superior a éstas", cita que, por lo excepcional, resulta sin duda singularmente expresiva, en cuanto no puede existir una resolución de carácter particular que vulnere las disposiciones de carácter general, sin que pueda entenderse que es contraria a tal tesis la sentencia de 15 de marzo de 1968, invocada en la apelada...». No descubro la razón por la que se cita el artículo 30 de la Ley de Régimen jurídico de la Administración del Estado. 
supervivencia indefinida constituría la aplicación de un positivismo manierista y hermético contrario a la generalidad del ordenamiento e incompatible con las normas de ia contratación administrativa».

En consecuencia, la sentencia de 15 de enero de 1971 considera derogado el Decreto de 25 de febrero de 1955 y de aplicación el artículo 57, 1, e) del Reglamento de Contratación de las Corporaciones locales.

En la misma línea de la sentencia que acabamos de citar, y precisando sus declaraciones, la sentencia (Sala Cuarta) de 19 de diciembre de 1973 declara que: «los Decretos de 13 de enero y 25 de febrero de 1955, disposiciones que consagran, podríamos decir que dogmáticamente, la equiparación de ambas contrataciones en lo concerniente a revisión de sus precios, inicialmente con un criterio prohibitivo que sólo parcialmente se ha excepcionado en disposiciones posteriores de carácter singular, aplicables a una y otra contratación... Pero a partir del Decreto-ley de 10 de octubre de 1963 y de la disposición del mismo rango de 4 de febrero de 1964, se quiebra aparentemente el cuidado paralelismo y sincronización normativa en la forma que hasta entonces había discurrido, al modificar ambos Decretos-leyes el criterio de irrevisabilidad hasta entonces imperante en los contratos del Estado, para sustituirle por la posible inclusión de una cláusula revisora, pero sin hacer extensiva esta modificación, ni solución alguna que se le equiparase a la esfera local».

«... el problema que plantea el hecho real o innegable de que el Decreto de 25 de febrero de 1955, suspensivo del apartado 1, e), del artículo 57 del Reglamento de Contratación de las Corporaciones locales, no haya sido mencionado en ninguna de las disposiciones dictadas posteriormente como legislación expresamente derogada. De tal hecho pudiera inferirse, como infiere y alega insistentemente la representación de la parte apelante, que a falta de una cláusula derogatoria expresa, el Decreto de 25 de febrero de 1955 continúa en vigor, y con él la suspensión del mencionado apartado del artículo 57 del Reglamento de Contratación de 1953, puesto que con arreglo al artículo $5 .^{\circ}$ del Código civil, las leyes solamente se derogan por otras posteriores.

La ausencia en leyes o decretos posteriores al de 25 de febrero de 1955 de una cláusula derogatoria de éste, no agota las posibilidades de que a su pesar haya perdido su vigencia; tanto por efecto de una derogación más que tácita en este caso implícita, como por 
hallarse intrínsecamente marcado el límite de su vigencia en su propio contenido. Analizando en primer término el mencionado efecto de derogación implicita, es necesario subrayar que aquel Decreto no nació como una disposición autónoma o independiente, sino que su publicación se produjo en estrecha vinculación con otras disposiciones, como sea el Decreto de 13 de enero de 1955 y la Ley de 17 de julio de 1945, de revisión de precios en los contratos del Estado, a la que ambos quedaron subordinados y en relación de dependencia tal que ambos fueron publicados por el Gobierno en uso de su autorización que el artículo 13 de aquella Ley le concedía para suspender las normas revisorias en ella reguladas, cuando las circunstancias futuras lo aconsejaren. Esta vinculación, dependencia y subordinación se expresa inequívocamente en la exposición de motivos del Decreto de 25 de febrero de 1955 y han sido ya valorados por esta Sala en sentencia de 15 de abril de 1961, cuando afirma que el punto referencial (tanto del Decreto de 13 de enero como del 25 de febrero, ambos de 1955, relativo el primero a la Administración central y el segundo a la local) es la Ley de 17 de julio de 1945, o en otros términos, que ambos Decretos traen causa de la citada Ley. Derogada expresamente ésta por los Decretos-leyes de 10 de octubre de 1963 (disposición adicional única) y de 4 de febrero de 1964 (disposición adicional segunda), es evidente que como consecuencia derivada de su subordinación a ella, también perdieron vigencia los Decretos citados, al no poder subsistir desligados y con carácter independiente de aquélla, consumándose de este modo su derogación implícita, pero no por ello menos eficaz.

Desde otro punto de vista, el Decreto de 25 de febrero de 1955. tampoco habría subsistido después del Decreto-ley de 4 de febrero de 1964, en razón a que su contenido intrínseco marcaba ya de un modo preciso el limite de su vigencia. En efecto, fue dictado en función de una sola y exclusiva finalidad: mantener el paralelismo en la regulación de la contratación administrativa, equiparando a las normas sobre revisión de precios previsto en la legislación vigente en la Administración central, las que deben regir en la esfera local, pues como según se dice en su exposición de motivos, "las razones que han impulsado al Gobierno a suspender la revisión de precios tiene la misma virtualidad en el ámbito local", por lo que "los principios inspirados de una y otra deben ser idénticos". Nos encontramos en rigor ante una disposición de duración limitada para 
consecución de un objeto de finalidad determinada; la armonización, siguiendo un idéntico criterio, de una y otra normativa. Esta finalidad actúa en la vida de la disposición que estamos analizando como principio determinante y condiciona y limita su vigencia a la subsistencia de la situación de equiparación que pretende mantener. Alterada y modificada esta situación y roto el paralelismo por efecto de los Decretos-leyes de 1963 y 1964, restablecedores para la Administración central del sistema permisivo de revisión, que los dos Decretos de 13 de enero y 25 de febrero de 1955 habían suspendido, el primero en la Administración central y el segundo en la local, este último quedó desde entonces vacío de contenido, perdiendo definitivamente su vigencia».

No cabe duda de que las normas jurídicas no sólo se extinguen por derogación (causa extrínseca) y mucho menos por sólo derogación expresa. La extinción de las normas puede tener lugar por causas intrínsecas (caducidad). Caduca la norma jurídica cuando habiendo sido dada para una cierta situación fáctica desaparece la situación origen de la misma, y también cuando cesa el estado de cosas que constituía su necesario presupuesto (14).

El Decreto de 25 de febrero de 1955 se dictó, evidentemente, porque se había publicado el Decreto de 13 de enero de 1955. El Decreto de 25 de febrero de 1955 pudo caducar si fue dado para mantener con respecto a la revisión de los precios de los contratos de la Administración pública una situación análoga en la esfera de la Administración local y en la esfera de la Administración estatal. Pero de acuerdo con la tesis jurisprudencial que acabamos de recordar, después de entrar en vigor los Decretos-leyes que regulan la inclusión de fórmulas polinómicas en los pliegos de condiciones de la Administración del Estado, si éstas se incluyen, el contratista podrá obtener la modificación del precio de su contrato, y si no se incluyen dichas cláusulas se le aplicará el artículo 1.593 del Código civil y no tendrá derecho a la revisión. En cambio, si en un pliego de condiciones de la Administración local se incluyen cláusulas de variación -lo que es perfectamente posible-, el contratista obtendrá la modificación del precio de su contrato, y si éstas no se incluyen, también tendrá derecho a la modificación del precio del contrato al amparo del artículo 57 del Reglamento de Contratación de las Corporaciones locales. El paralelismo se rompe.

(14) CASTÁN, J., Derecho civil español, común y foral, Madrid, Reus, 1951, tomo I, volumen I, pág. 388. 
III. EL DECRETO DE 31 DE MAYO DE 1974 REGULADOR DE LA REVISION DE PRECIOS DE LOS CONTRATOS DE LA ADMINISTRACION LOCAL

1. Finalidad del DeCreto DE 31 de mayo de 1974

El Decreto de 31 de mayo de 1974 (número 12.983, «Boletín Oficial del Estado» de 3 de julio de 1974) se propone, según su preámbulo, la «unificación de criterios» sobre la revisión de los precios de los contratos en las esferas de la Administración estatal y local, para lo cual «estima oportuno declarar de aplicación a las Corporaciones locales, con las adaptaciones del caso, la normativa que hoy se aplica en la materia a la Administración del Estado". En consecuencia, el artículo 1. ${ }^{\circ}, 1$, del citado Decreto dispone: «Serán aplicables a la Administración local las disposiciones contenidas en el Decreto-ley dos mil novecientos sesenta y cuatro, de 4 de febrero, y sus normas complementarias sobre revisión de precios en los contratos de obras del Estado, con las modificaciones que se prevén en el presente Decreto» (15).

El artículo 1..$^{\circ}$ del Decreto-ley de 4 de febrero de 1964 establece que en «los contratos de obras del Estado y organismos autónomos dependientes del mismo cuya cuantía sea superior a cinco millones de pesetas y que se formalicen con posterioridad a la fecha de promulgación de este Decreto-ley mediante subasta, concursc o concierto directo, podrán incluir en sus pliegos de condiciones particulares y económicas una cláusula de revisión de precios, cuyos requisitos y alcance se determinan en los artículos siguientes».

\section{La naturaleza juRídica del DeCReto de 31 de mayo de 1974}

Creo que está fuera de toda duda que las fórmulas tipo o polinómicas previstas y reguladas para el Estado por el Decreto-ley de 4 de febrero de 1964 - hoy recogidas y unificadas por el Decreto de 19 de diciembre de 1970 ( «B. O. E.» de 29 de diciembre de 1970)-, y para las Administraciones locales por el Decreto de 31 de mayo de 1974, son verdaderas cláusulas de variación de los precios de

(15) La principal norma complementaria del Decreto-ley de 4 de febrero de 1964 es el Decreto de 11 de marzo de 1971, con un contenido de gran interés. 
los contratos, pues con ellas se revisan automáticamente los precios de los contratos. Estas cláusulas, como antes hemos expuesto, por su propia naturaleza, no contradicen los principios que las leyes y reglamentos establecen para la contratación de la Administración del Estado y de las Administraciones locales, por lo que en los contratos celebrados por las Administraciones públicas podían incluirse aun antes de dictarse las disposiciones citadas. Tanto el artículo $1 .^{\circ}$ del Decreto-ley de 1964 como el artículo $1 .^{\circ}, 2$, del Decreto de 1974 emplean con toda exactitud la expresión de que se "podrán incluir» en los pliegos de condiciones económico-iurídicas cláusulas de revisión de los precios con las características que en dichas normas se establecen. Las disposiciones citadas no tratan de abrir una posibilidad que antes no existía, sino de explicar cómo deben ser las cláusulas que las Administraciones públicas pueden incluir en sus contratos, sus limitaciones y los mecanismos para su funcionamiento. Por eso pienso que también pueden incluirse cláusulas de variación en los contratos cuya cuantía sea inferior a la que en dichos preceptos se señalan (16).

Me parece que los repetidos Decreto-ley y Decreto son normas explicativas. Ni siquiera permisivas, y desde luego sus normas no son imperativas en cuanto a la inclusión de las cláusulas, aunque sí en cuanto al procedimiento para adoptar los acuerdos de su inclusión en los pliegos (17). Con anterioridad a las disposiciones que analizamos, dicha inclusión se hubiera llevado a cabo de conformidad con las normas generales del procedimiento administrativo. Publicado el Decreto-ley de 4 de febrero de 1964, hubiera podido aplicarse como norma supletoria por las Corporaciones locales, en virtud de lo dispuesto en la disposición adicional segunda de su Reglamento de Contratación(18). El que las normas que examinamos sean explicativas no quiere decir en ningún caso que no sean muy útiles y convenientes.

(16) Véase artículo 1. del Decreto-ley de 1964 y artículo $1 .^{\circ}, 3$, del Decreto de 31 de mayo de 1974.

(17) Artículo 2. del Decreto de 31 de mayo de 1974.

(18) Angulo González, M. A., "Revisiones de precios en los contratos de las Corporaciones locales», Revista de Estudios DE LA VIDA Local, núm. 175, 1972, páginas 500 y sigts. 


\section{LAS FÓRMULAS TIPO}

El artículo 3..$^{\circ}$ del Decreto de 31 de mayo de 1974 dispone que "las Corporaciones locales que cuenten con los medios técnicos adecuados podrán elaborar fórmulas tipo para las distintas clases de obras a su cargo que sirvan para calcular el coeficiente de revisión, ajustándose a lo previsto en el párrafo segundo del artículo tercero del Decreto-ley dos mil novecientos sesenta y cuatro, y siempre que, en su conjunto, las fórmulas así elaboradas no supongan incrementos superiores a los que resulten de las que rijan en el Estado para obras análogas. Tales fórmulas tipo deberán ser publicadas en el «Boletín Oficial» de la Provincia respectiva, y serán revisadas cada dos años como mínimo.

Cuando las Corporaciones locales no hagan uso de la facultad prevista en el apartado anterior, regirán a dicho efecto las fórmulas aprobadas para las obras del Estado por Decreto de la Presidencia del Gobierno tres mil seiscientos cincuenta/mil novecientos setenta, de 19 de diciembre, con sus modificaciones posteriores.

Los índices oficiales de precios que sirvan de base para las revisiones que se lleven a cabo serán los que se publiquen en el "Boletín Oficial del Estado», conforme a lo dispuesto en el artículo noveno del Decreto-ley dos mil novecientos sesenta y cuatro".

4. El Decreto de 31 de mayo de 1974 y la vigencia del artículo 57, 1, e), del Reglamento de Contratación de las Corporaciones LOCALES

El preámbulo del Decreto de 31 de mayo de 1974 expone de manera resumida el problema de la vigencia o no del artículo 57, 1, e), del Reglamento de Contratación de las Corporaciones locales, y dice que "es lo cierto que hasta el momento no se ha derogado expresamente el de 25 de febrero de 1955, antes citado, que suspendió en su vigencia la aplicación con carácter general del sistema de revisión de precios en la Administración local».

En el texto del Decreto de 31 de mayo de 1974 no se contiene la menor alusión al artículo 57, 1, e), del Reglamento de Contratación de las Corporaciones locales. Pudiera pensarse que el Gobierno cree que la vigencia de este último precepto continúa en suspenso 
y que por esto regula la inclusión de fórmulas tipo en los pliegos de condiciones de los contratos de las Administraciones locales para revisar sus precios en determinadas circunstancias. Pero también es cierto que el Tribunal Supremo, en algunas sentencias, no lo estima así, pues aunque considera que el Decreto de 25 de febrero de 1955 no ha sido derogado de forma expresa, afirma que lo ha sido implícitamente o que ha caducado. Lo que me parece indudable es que la posibilidad de incluir en los pliegos de condiciones fórmulas tipo para la variación de los precios no tiene ninguna repercusión sobre el problema de la vigencia del artículo 57, 1, e), del Reglamento de Contratación de las Corporaciones locales. La inclusión de dichas fórmulas -que repetimos no es obligatoriapodrá disminuir el planteamiento de cuestiones entre los contratistas y las Administraciones locales sobre la modificación de los precios de los contratos, pero en los contratos en cuyos pliegos de condiciones no se incluyan fórmulas polinómicas de variación de los precios podrá suscitarse el irresuelto problema de la aplicación o no del artículo 57, 1, e), del Reglamento de 9 de enero de 1953. Sería, pues, conveniente resolver por medio de una disposición reglamentaria la cuestión de la vigencia o no de este precepto del Reglamento de Contratación. Cabría suprimir definitivamente la revisión de los precios amparada en un precepto reglamentario; pero me parece más oportuno sustituir el artículo 57,1, e), por una regulación que establezca la variación automática de los precios de los contratos en función del cambio de la coyuntura económica. 
REVL-1974, núm. 184. BOQUERA OLIVER, JOSE MARIA. LA REVISION DE PRECIOS DE LOS C... 